\title{
ARTIFACT
}

\section{Left to Our Own Devices}

by Johan Redström, Danish Centre for Design Research, Copenhagen, and Interactive Institute, Göteborg

Keywords: Design philosophy, Interaction design, Aesthetics, Artificial-Biological

At times it appears as if artifacts are best described as 'not nature' but, even at that, the boundary begins to blur as we consider developments in areas such as genetics and biotechnology where biology and design begin to merge. The realm of artifacts has grown, and so have notions of what they are and could be. Our world is becoming ever more an artificial one, understood as 'made by' rather than 'given to' us. Research is no longer if ever about describing what is, but increasingly about exploring what could be and in many cases therefore also what will be. And so, the subject of design, that of "the initiation of change in man-made things" as J. C. Jones (1992), p. 6) put it, has expanded how could it not?

Seen from inside, the design space of manmade things has grown beyond our scale in all directions. We create things in laboratories, such as molecules, that exist for such short time spans that they are on the very threshold of existence. We create stuff that will be around for longer than we will exist, perhaps even as a species. And with miniaturization of technology, we create things at a scale far smaller than we can relate to with our own senses. No wonder this expansion of the subject of design causes difficulties. In what follows, I will speculate a bit about the 'made' part of the notion of 'manmade things', as this development seems to imply some changes also to how we may think of acts of design and use.

\section{NOT NATURE}

Whatever our ideas about the relation between the living and the artificial as such, it seems that our understanding of nature plays a certain role in the development of the artificial. In relation to design research, Herbert Simon considered biology as a role model for his envisioned sciences of the artificial, which among other things could be seen in his ideas concerning methods for scientific enquiry through optimization, how nature can be considered as evolving towards the purposeful and advantageous (Simon, 1996).

In everyday practice, we might talk about the evolution of a concept or a design, or about structuring the design process in a way that includes several 'generations' of suggestions and sketches, where we select from each generation the ones most interesting to develop further. Another example is how the central role of functions in our understanding of technical objects has a certain resemblance to our way of understanding the living organism as composed of parts, e.g. organs, with certain functions (cf. Cummins, 1975; Kroes, 2001). The roots of this comparison go rather deep in our history, as in the works of one our early 'biologists':

... if some tool, say an axe, were a natural body, its substance would be being an axe, and this would be its soul. And if this was separated from it, it would not continue to be an axe ... if the eye was an animal, then sight would be its soul.... And the eye is the matter of sight, so that when sight leaves it it is no longer an eye except homonymously, in the way of a stone or painted eye. (Aristotle, 1986, pp. 158f)

\section{LIFE FORM}

Considering this migration of ideas from biology - or rather, from our understanding of 'living' things - to our understanding of 'man-made' things (and back), there is one aspect of the living not explored to any significant extent in design: that of growth and becoming.

Of course, design to some extent deals with development over time, but our basic understanding seems typically centred on what is, 
what it is that designers create. Now, if the reason for thinking this way is because our materials used to be rather static in nature, it seems that digital technologies will challenge this view as the things we design no longer necessarily stay the way we left them.

\section{Consider a typical personal computer as an} example: though the device was made and set up by the manufacturer, over time the user fills it with new software, documents and other files, effectively making it into something of a 'personal' device. Does this mean that the act of designing the computer has been stretched out, and that to use it now also means to design it, as it is the user who, so to speak, is the creator of its current form?

That there are layers of design and use is in itself not new: a craftsperson 'uses' our material to build, say, a bowl, that someone then 'uses' to make food, etc. But in this case the 'form' of the made thing, the bowl, remains and whereas the user interprets and perhaps redefines the use of the bowl, we would hardly think that he/she alters its form. The personal computer, however, seems a bit different in this respect.

\section{Perhaps one could object and point out that a} user typically assembles already given pieces, e.g. readymade software, and that this is not really the same as designing the thing. But then again, a significant part of designing a computer is assembly in the first place: hardware components are put together, code is being reused as new applications are developed, etc. Just think of how object-oriented programming languages, like Java with all its libraries, work.

It seems hard to make a proper distinction between design and use on the basis of vague notions of 'originally created by $X^{\prime}$ ', and if we try the assumption that 'designer' here means the one(s) responsible for a particular structure of parts, it seems that 'to use' will be rather similar to 'to design'. Yet, intuitively, there seems to be a certain difference between using information technology and designing it, just as there seems to be a difference between designing a house and living in it, even though the latter includes furnishing it, modifying the interior, repainting the exterior, etc. Does such a distinction between design and use start to break down as we try to understand what happens to the form of an artifact capable of significant change during its life-span?

Perhaps we can think of use as a kind of cultivation. To use a computer is a bit like farming: one does not create the plants but grows them; one does not create the earth but takes care of it.

Digging deeper in the dirt, we might find something in the works of our early biologist, Aristotle. As it happens, form is a central notion not only in design but in Aristotle's philosophy as well. His distinction between form and matter may appear rather straightforward, explaining the difference between the way something has been made and with what, e.g. how two bowls can both be made of copper but differ in form, or how two bowls may have the same form though be made out of different materials. While this works well for static objects, it does not account for why certain things change something rather central to the living thing. For instance, why do acorns turn into oaks, and indeed why do acorns turn into oaks and not into hens for that matter?

Trying to explain change and growth, Aristotle somehow had to introduce 'causes', or mechanisms, for change. What is interesting, at least from our present point of view, is that he did so by expanding upon his conceptions of form and matter: 'Thus matter and form regarded as factors in a process of change become potentiality and actuality (or potency and act)' (0'Connor, 1964, p. 51). To (over-) simplify we may then say that, through its matter and form, a given thing carries with it not only its current state but also a set of potential other states. Obviously, it is not the current explanatory powers of these ideas in biology that interests us, but the notion of form and matter as not only static features but factors for change.

\section{BUT LET US CULTIVATE OUR GARDEN}

According to notions of design as 'the initiation of change in man-made things' (Jones, 1992), design in general seems to be a lot about changing things. While that might be true of the objectives of design practice, typical notions of form and matter are in many ways similar to Aristotle's account of the static object. Consider the term 'man-made' what does made refer to here? That it was once made and then remains that way (cf. Jones, 1988)? 
Certainly, notions of design processes are very important, but typically such ideas relate to the practice of design and not so much to the actual form of the objects created. There is, of course, also the design of actual processes, but these are often accompanied by ideas such as that the 'what' we are designing is something like the 'user experience' or a 'communication process'. In such cases, design seems to be turning away from the things themselves and, when it comes to the actual artifacts designed to support these processes, notions of form are still rather static.

Still, this has some possibly interesting implications for how we think about formgiving. Though it may initially be tempting to think of this expanded notion of form as a way of simulating the workings of the living, e.g. as done within studies of learning processes in artificial intelligence, we need not think of it in such terms. Perhaps we can simply think of it as expansion of our current notions of 'form', so as to include not only giving form to the existing but also the shaping of the possible, of what might become.

It seems rather strange to say that we give form to the possible, not necessarily knowing now precisely what it might be yet, as the example of the personal computer above illustrates, we already deal with it in practice. Here, it seems we have created something that not only has a certain current form, but also a set of possible future forms. And as with acorns and eggs, a computer cannot become any thing, though it certainly can be become very many different things.

Looking towards more established areas of design, we can perhaps recognize this issue in the way one talks about 'using' materials in design, although here it would be the material itself that defines the space of possible future forms through its characteristic properties. One can certainly do very many things with wood or ceramics, but one cannot do any thing. Is this the way one should try to understand artefacts like the personal computer: is this like creating 'material' that someone else will 'use' to design his/her own thing?

A notion of form-giving as not only including the actual but also the potential is in many ways both trivial and rather intriguing as is Aristotle's original distinction. Perhaps it can help us discuss why there seems to be a difference between designing and using an artifact, as this, then, can be seen as setting up a space of possible future states on one hand, and then realizing such states on the other.

Such notions of form and form-giving could therefore perhaps also be helpful in relation to our other concern, that of understanding how design and use seemingly are layers of acts relative to each other. For instance, we may think we 'design' a computational device that they will be 'using', but the people over here think we are 'using' their hardware components to build it. From one perspective what is being done is 'design', from another perspective it seems to be a matter of 'using' something.

It seems that it is not only the design space that has been stretched in all directions as a result of technology development in general and of digital technologies in particular: so too have acts of design and use. And so, in the end, we will all be left to our own devices.

\section{REFERENCES}

Aristotle (1986). De Anima (On the soul) (H. Lawson-Tancred, Trans.). London: Penguin Books.

Cummins, R. (1975). Functional analysis. Journal of Philosophy, 72, 741-764. (Reprinted in Sober, E. (Ed.) (1994). Conceptual issues in evolutionary biology (2nd ed.) (pp. 49-69). Cambridge, MA: MIT Press.

Jones, J. C. (1988). Softecnica. In J. Thackara (Ed.), Design after modernism: beyond the object (pp. 216-226). London: Thames \& Hudson.

Jones, J. C. (1992). Design methods (2nd ed). New York: Wiley.

Kroes, P. (2001). Technical functions as dispositions: a critical assessment. Techné (Electronic Journal of the Society for Philosophy and Technology), 5(3), 116.

O'Connor, D. J. (1964). Aristotle. In A critical history of western philosophy (pp. 36-61) (0'Connor, D. J., Ed.). New York: Free Press.

Simon, H. A. (1996). The sciences of the artificial (3rd ed.). Cambridge, MA: MIT Press.

\section{CORRESPONDENCE}

Johan Redström, Visiting Associate Professor, Danish Centre for Design Research, 
Academy of Fine Arts, School of Architecture,

Philip de Langes Allé,

1435 Copenhagen, Denmark.

E-mail: Johan.Redstrom@karch.dk

Published online 2006-04-21

ISSN 1749-3463 print/ ISSN 1749-3471

DOI: $10.1080 / 17493460600610863$

(C) 2007 Artifact 